British Journal of Psychiatry (1991), 159, 439-449

\title{
Correspondence
}

Editor: Ian Pullen

Contents: Definition of chronic fatigue syndrome (CFS)/Tardive dystonia: male:female ratio/Suicide risk for parasuicide repeaters/Eating disorders in Asian girls/Motor disorder in severe mental handicap/Delusional jealousy in paranoid disorders/ Is schizophrenia disappearing?/Lateral ventricular size, educational level and patient subtypes in schizophrenia/Abreaction before ECT?/Steroidinduced catatonia/Three thousand days of pregnancy/Tardive dyskinesia, depression and ECT/A case of depression responding to spontaneous epilepsy but not ECT/Nifedipine-induced depression/Bizarre delusion and post-hemiplegic hemidystonia.

\section{Definition of chronic fatigue syndrome (CFS)}

SIR: We were interested to read Serra's comments about criteria for chronic fatigue syndrome (CFS) and the problems faced in such research (Journal, May 1991, 158, 717).

CFS is a widely used term, but is probably not wholly satisfactory as it represents an operational definition relying on inclusion and exclusion criteria that may well change with increasing knowledge of the condition. This is exemplified by the fact that there are three major criteria for CFS, the original criteria (Holmes et al, 1988), the Australian criteria (as published in Lloyd et al, 1988) and the most recent Oxford Consensus criteria (Dawson, 1990).

The predictive validity of these various systems needs to be examined more closely with regard to the position of concurrent psychiatric morbidity and other clinical features, particularly the complaint of fatigue. We are in the process of completing an 18-month follow-up study in CFS and other diagnostic groups, e.g. major depression. Forty-six consecutive referrals to a research clinic were studied. All had persistent fatigue which prevented or impaired work, and a median $\mathbf{3 6}$ months of illness which would have met the recent consensus criteria for CFS. Also studied were 41 out-patients with DSM-III-R major depression (28 were new referrals, i.e. first episode). At follow-up (information was available on 42 CFS patients and all 41 depressed patients), only 29 of the CFS patients (73\%) and 38 of the major depression patients $(92.7 \%)$ would still have met these criteria. The major reason for exclusion of CFS patients was development of physical illness in nine patients (four cases of connective tissue disease and one of connective tissue tumour) and psychiatric illness in another four patients (two of schizophrenia). There were three patients in the major depression group who later changed diagnosis (two bipolar affective disorder, one schizophrenia). This shows the relatively poor predictive validity of the new consensus criteria for CFS compared with those of major depression.

Regarding Serra's point about psychiatric illness and its place in the definition of CFS, if we had followed the original CFS criteria (Holmes et al, 1988), only seven patients would have been included, the others being excluded on the grounds of concurrent psychiatric morbidity. However, the predictive validity of the criteria would actually have been worse, as only two of these patients would still have met the criteria. This is because there would still have been the same four psychiatric episodes that developed by 18 months and one patient with connective tissue disease would have been excluded.

It could be argued that these disorders in the CFS group are actually separate and represent comorbidity, but we took the view that these were probably sufficient to explain the original complaint of fatigue. It is possible that the initial complaint of fatigue was a prodromal phase of other physical and psychiatric illness in some patients. This underlines the importance of regular review from medical and psychiatric standpoints of patients with an original diagnosis of CFS. If such findings are replicated it also urges a more cautious view to be taken of the role of somatisation and attribution in CFS.

\footnotetext{
DAwson, B. (1990) Consensus in research into fatigue syndrome. British Medical Journal, 300, 832.

Holmes, G., Kaplan, J., Gantz, N., et al (1988) Chronic fatigue syndrome: a working case definition. Annals of Internal Medicine. 108, 367-369.
} 
LLOYD, A. R., WAKEFIELD, D., Boughton, C., et al (1988) What is myalgic encephalomyelitis? Lancet, $i, 1286-1287$.

St Charles Hospital

London W10 6DZ

St Mary's Hospital

London

Dulwich Hospital

London

\section{Tardive dystonia: male:female ratio}

SIR: I read with interest the article by Cunningham Owens (Journal, May 1990, 156, 620-634), particularly the part about tardive dystonia, since in our clinic, we are studying this serious, often social, and sometimes physical, invalidating side-effect of neuroleptics. I was surprised by their comment that: "Also there is no known difference in prevalence between the sexes". Six publications suggest that, on the contrary, there is a difference in prevalence between the sexes showing male:female ratios as follows: Burke et al (1982), 2.5:1; Gimenez-Roldan et al (1985), 1.2:1; Friedman et al (1987), 4:1; Gardos et al (1987), 3:1. Yassa et al (1989), 3:1. This gives an average figure of 2.4 males to every female with tardive dystonia. Only one retrospective publication (125 patients, 30 with tardive dystonia) found an equal ratio for men and women (Miller \& Jankovic, 1990).

This difference in male:female ratio is probably one argument for considering tardive dystonia to be a separate entity from tardive dyskinesia, an opinion which has been suggested in several articles. As Yassa et al (1989) write: "tardive dystonia seems to be more common in young male patients while severe tardive dyskinesia is more common in older women".

BURKE, R. E., FAHN, S., JANKOVIC, J., et al (1982) Tardive dystonia: Late-onset and persistent dystonia caused by antipsychotic drugs. Neurology, 32, 1335-1346.

Gimenez-Roldan, S., Matbo, D. \& BARtolom, P. (1985)

Tardive dystonia and severe tardive dyskinesia: a comparison of risk factors and prognosis. Acta Psychiatrica Scandinavica, 71, $488-494$.

Friedman, J. H., Kurcharski, L. T. \& Wagner, R. L. (1987)

Tardive dystonia in a psychiatric hospital. Journal of Neurology. Neurosurgery and Psychiatry, 50, 801-803.

GARDOS, G., COLE, J. O., SChutebolK, S., et al (1987) Comparison of severe and mild tardive dyskinesia: implications for etiology. Journal of Clinical Psychiatry, 48, 359-362.

YASSA, R., NAIR, V. \& IskandAR, H. (1989) A comparison of severe tardive dystonia and severe dyskinesia. Acta Psychiatrica Scandinavica, 80, 155-159.
Miller, L. G. \& JANKovic, J. (1990) Neurologic approach to druginduced movement disorders: a study of 125 patients. Southern Medical Journal, 83, 525-532.

Dr David Ricardo Capriles Clinic

Mohikanenweg 8, Curaçao

Netherlands Antilles

\section{Suicide risk for parasuicide repeaters}

SIR: Stocks \& Scott's retrospective study on people who repeatedly harm themselves deserves comment (Journal, March 1991, 158, 375-378). Their conclusion that people who repeatedly harm themselves are not as likely to die by suicide as has until now been thought cannot be sustained, and is dangerously misleading.

Their sample size was 42 , and follow-up was only one year. The usual figure cited is that $1 \%$ of unselected hospital parasuicides kill themselves each year (Weissman, 1974). Using a follow-up period of only one year they would have needed more than 177 subjects with zero suicides to achieve a statistically significant result upon which they could conclude that the suicide rate in repeaters was less than the usual $1 \%$ rate (assuming a mean of 1 , a standard deviation of 0.3 and alpha equal to 0.05 ).

Alternatively, staying with this small sample size of 42 subjects they would have required 4.2 years of follow-up without a completed suicide to be able to claim a statistically significant lower death rate than 1 per 100.

Finally, 37 of their 42 subjects engaged in further self-harm within three months. We accept this is not surprising since they were selected as repeaters. What is surprising is their statement (with the obvious inference) that "Intervention, however problematic, may be justified if such patients are likely to kill themselves. None of the sample killed themselves ..." Hospital admission or other interventions may or may not be effective - little research has adequately addressed this issue. For the present, we have a problem of chronically suffering individuals imposing a considerable burden on emergency and other services. Intervention is justified!

Wesssman, M. M. (1974) The epidemiology of suicide attempts 1960-1971. Archives of General Psychiatry, 30, 737-746.

Division of Psychiatric Services

C. CANTOR

State Health Building

147-163 Charlotte Street

GPO Box 48, Brisbane 4001

Queensland, Australia

P. BURNETT

Queensland University of Technology, Australia 